\title{
REPORT OF AN UNUSUAL CASE OF ORBITAL TUMOUR
}

\author{
BY \\ W. H. Gow, M.B., Ch.B. \\ EYE DEPARTMENT OF THE MOUKDEN MEDICAL \\ COLLEGE AND HOSPITAL
}

Miss W., aged 18 years, came to the Moukden Hospital on April $30 ; 1931$, with a huge tumour in her left orbit which was incompletely covered by the lids. It was concealed by a large eye shade which she was only, with difficulty, induced to remove.

She gave the following history:-When she was 13 years of age, one summer morning her left eye was noticed to be a little larger than its fellow and at the same time she accidentally discovered that she could not see with this eye. As far as she could recall the eyeball had gone on increasing, though very slowly, in prominence and in size. All the time, however, she suffered no great pain, though the feeling of tightness was always present.

On removing the large eyeshade there was to be seen an enormous tumour which, occupying the left socket and extending in all directions, protruded far beyond the limit of the orbit even though the socket itself was twice as large as that of the sound side. The upper and lower lids were tightly stretched, though normal in colour. The superficial veins stood out rather prominently. The upper lid was still moveable; but the lower palpebral conjunctiva adhered to the lower quadrant of the eyeball. This may have been due to the scraping done by the old fashioned Chinese practitioner from whom the patient received treatment four months before admission.

The cornea was completely covered by a thick, yellowish scab, which was due to the constant irritation resulting from the incomplete closure of the lids. No anterior chamber, iris or pupil could be seen. Sight nil.

The length of the palpebral aperture was $6.5 \mathrm{~cm}$., that of the right eye was only $3.3 \mathrm{~cm}$.

The following measurements were made before the tumour was removed. The circumference of the tumour as far posteriorly as it was possible to measure it was $19.5 \mathrm{~cm}$. The greatest vertical height was $5 \mathrm{~cm}$. The anterior pole (formed by the scab) projected forward from the temporal angle $5 \mathrm{~cm}$. This point was $4 \mathrm{~cm}$. in front of the cornea of the right eye.

The vision of the right eye was normal, for distance $6 / 6$ and for near, Jaeger I. The optic disc was of normal colour and the retinal arteries and veins of normal calibre. 
Unusual Case of Orbital Tumour

521

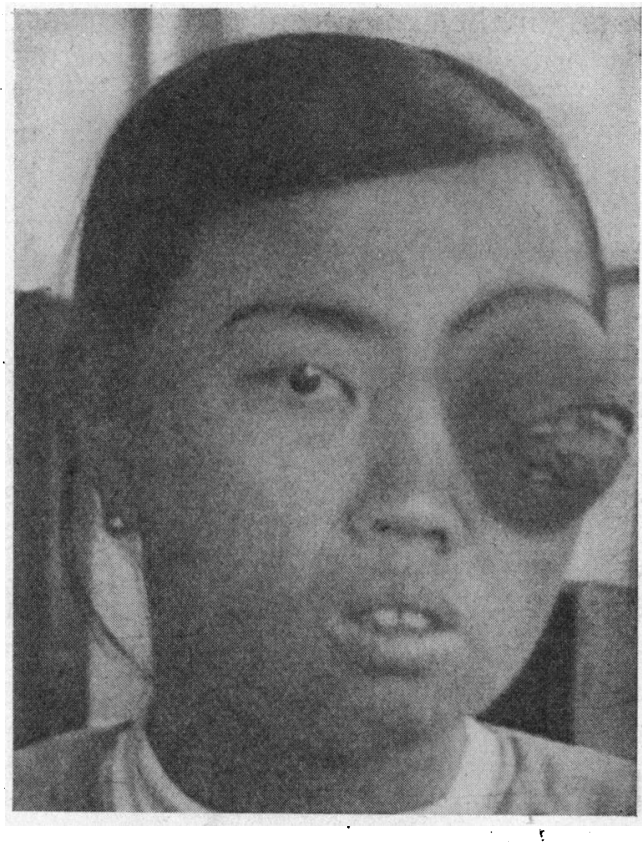

FIG. 1.

Photograph (enlarged) of the patient before operation.

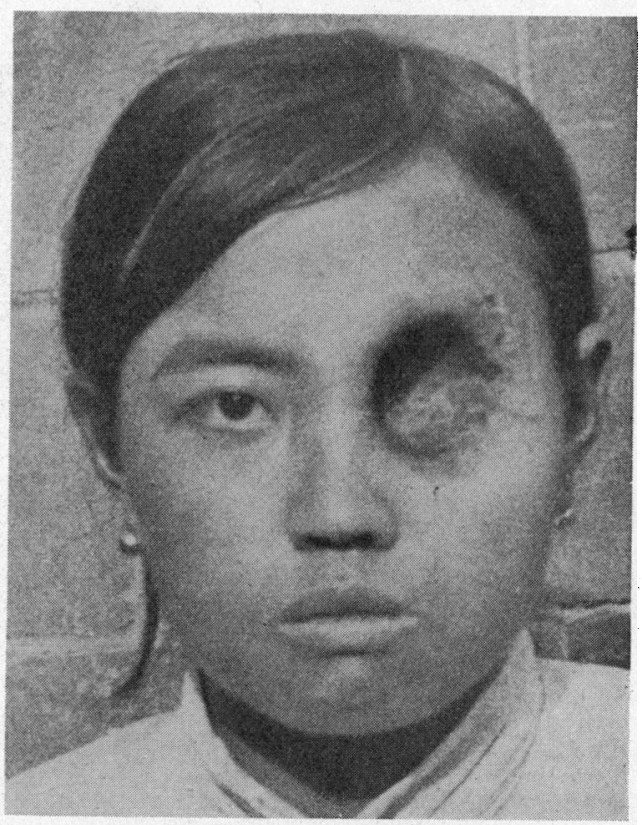

Fig. 2.

Photograph (enlarged) of the patient after operation. 
Without hesitation the patient consented to operation. Exenteration was performed on May 3, 1931. The tumour came out very easily, having no adhesions to the neighbouring tissues. There was not much bleeding. The patient made an uninterrupted recovery and left hospital after a fortnight's stay.

Figs. 1 and 2 are from photographs of the patient before and after operation.

\section{Pathological Report}

Macroscopic examination. The tumour is ovoid, the anteroposterior diameter being greater than the lateral or vertical diameters. Near the anterior pole are the edges of the upper and lower lids which leave a fissure about $2 \mathrm{~cm}$. in height and $6 \mathrm{~cm}$. in length. The fissure is covered with a roughened surface to the centre of which is attached a scab.

Dimensions. Circumference in antero-posterior plane $21 \mathrm{~cm}$.; circumference in lateral plane $18.8 \mathrm{~cm}$.; antero-posterior diameter $7.5 \mathrm{~cm}$.; lateral and vertical diameters $5.5 \mathrm{~cm}$.

On opening the tumour, it was found to be a cyst containing about 90 c.c. of thick, brownish fluid. The wall of the cyst was fairly uniform in thickness in the posterior half, but anteriorly it was thickened considerably with the remnants of the eyeball, the thickened cornea and conjunctiva, and parts of the lids.

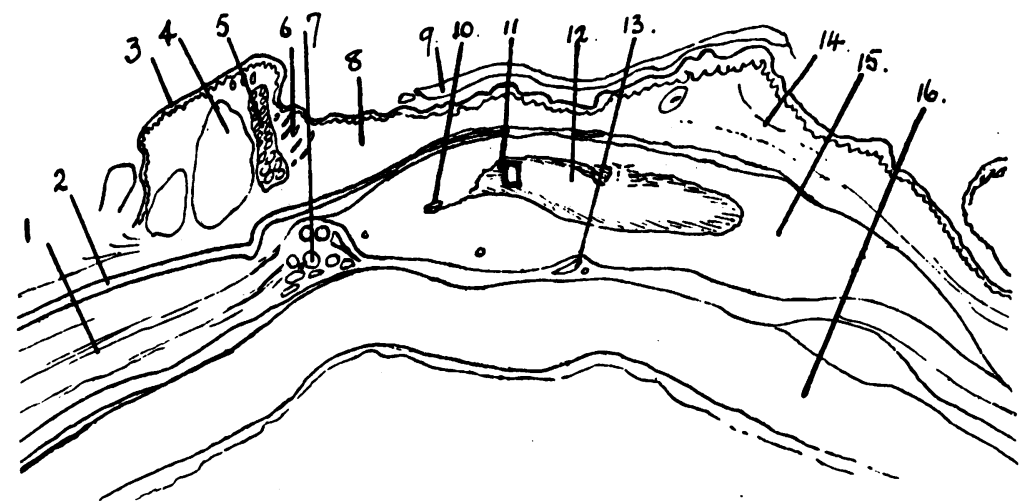

FIG. 4.

(X4) Section of the Anterior Pole of the Cyst. Schematic. 1. Loose connective tissue. 2. Band of dense connective tissue.

3. Squamous epithelium with papillae. 4. Skeletal muscle. 5. Sebaceous glands with a few hairs. 6. Mouths of sebaceous glands the epithelium being very irregular here and the sub-epithelial tissue infiltrated with round cells. 7. Group of small vessels with one small nerve. 8 . Round celled infiltration. 9. Cornification. 10. Small nerve. 11. Pigmented tissue-remnants of choroid. 12. Remnants ot retina. 13. Small nerves. 14. Round celled infiltration with many dilated vessels. 15. Dense connective tissue. 16. Wall of Cyst. 


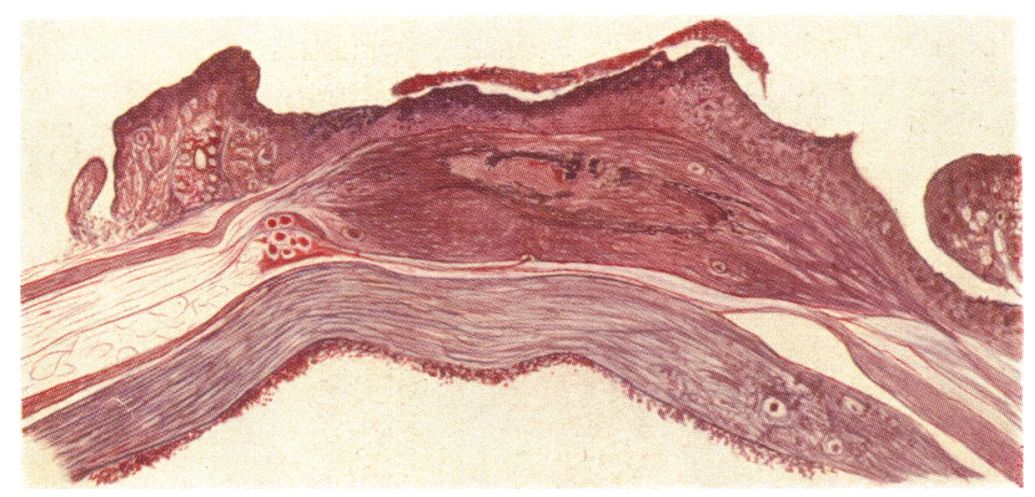

Fig. 3.

(X4) Section of the Anterior Pole of the Cyst, showing epithelial surface and below this the eyeball which has been completely collapsed by the pressure of the cyst behind it. Choroid remnants are prominent with their black pigment.

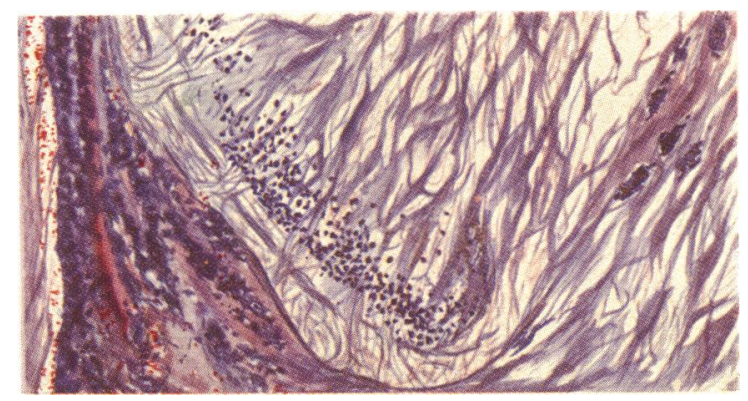

Fig. 5.

( $\times 50$ approx.) Retinal and choroidal tissue from the rectangle in Fig. 4.

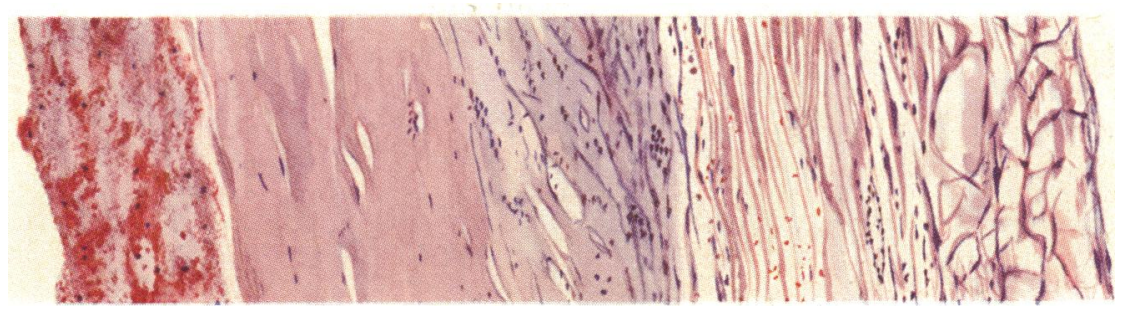

FIG. 6.

( $\times 50$ approx.) Wall of Cyst. Typical section with no epithelial lining showing, this having been destroyed by the haemorrhage. 
The wall was firm and strong with a blackish-brown coating of coagulated and degenerated blood on its inner surface.

The wall of the cyst at the anterior pole was similar to that elsewhere, but anterior to it lay an elongated oval body with a clearly-defined very white wall of irregular width (Fig. 4, 15). This enclosed a black mass (Fig. 4, 11) in the centre of which there was a smaller, whitish body (Fig. 4, 12). The large, clear white body was what remained of the sclerotic coat of the eyeball, the dark mass the degenerated choroid coat and the small central whitish body the retinal remains.

The cornea and conjunctiva were greatly thickened. To the cornea was attached a cornified scaly mass. The edges of the lids were greatly thickened and showed a few eyelashes.

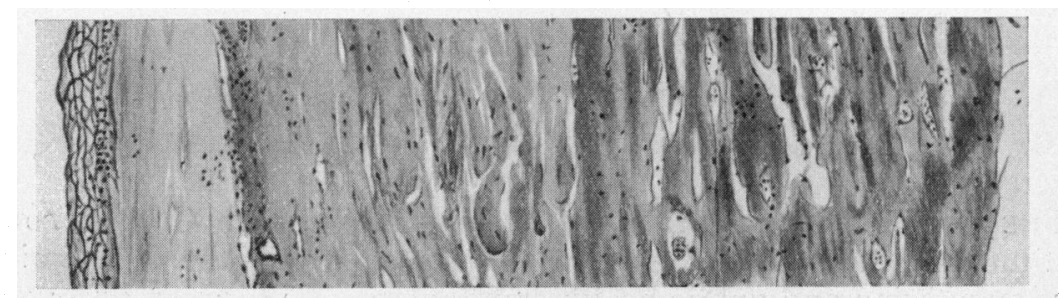

FIG. 7.

( $\times 50$ approx.) Wall of Cyst at one point.

Microscopic examination. Fig. 3 represents a drawing of the anterior wall of the cyst with the flattened eyeball lying in front of it.

Fig. 4 is from a similar section and gives a schematic representation of the different parts.

Fig. 5 represents the small rectangular area marked out in Fig. 4. The arrangement of the nuclei in the non-pigmented part confirms the view that this is really retinal tissue, and that the cyst originated posterior to the eyeball and had gradually forced the eyeball forward and flattened it out on its anterior pole as it grew still larger.

Figs. 6 and 7 represent the wall of the cyst at other points. The first sections made were all similar to Fig. 6, which shows the fibrous wall with blood clot and degenerating blood on its inner surface. After cutting out several small pieces of the wall and sectioning them Fig. 7 was obtained, where the cyst's original lining membrane is still intact and undamaged by the haemorrhage which must have taken place into the cyst. This lining is composed of squamous epithelium and the cyst is, therefore, an epithelial or dermoid cyst. 
While cysts of this type are often found in the region of the eye the interest of this case lies, first, in the fact that it must have arisen posterior to the eyeball, and secondly, in the size to which it has grown causing complete flattening of the eyeball as seen in Figs. 3 and 4.

In the literature on tumours of the orbit to which I have had access I have not been able to find a case similar to this one.

I wish to express my thanks to Dr. Garven for the notes on the pathological examination and also to $\mathrm{Mr}$. Li Hung Hsin for the drawings.

\title{
TRACHOMA IN THE INDIANS OF WESTERN CANADA
}

\author{
BY \\ DR. J. J. WALL \\ DEPARTMENT OF INDIAN AFFAIRS, CANADA
}

THE trachoma situation in the Indians of Western Canada constitutes a serious problem when viewed from the economic, humanitarian and public health standpoints. To form an adequate conception of the visual devastation wrought by this disease together with its complications and sequelae, one should really visit some of the Western Settlements.

The total economic loss resulting from the ravages of the disease, is difficult to compute at the present time. Many Indians are in their transitional period in various parts of the West. Hunting and trapping as a sole source of livelihood for these people has largely disappeared, being replaced by agriculture and stock raising on Reserves placed aside for their use. Civilization with all its resultant obligations and dangers to these peoples has definitely supplanted the old régime. Huts and houses, frequently overcrowded and usually badly ventilated in the colder weather, have replaced the admirable teppee and tent. Every effort must be expended to check trachoma and the economic loss engendered by the disorder in those individuals whose ultimate disability precludes any possibility of self-support. Failing this, contributions must be forthcoming from the public treasury toward such an individual's support which would undoubtedly constitute a considerable financial outlay by the country in the future.

One must take cognizance of the humanitarian aspect of this malady. The suffering of many of these afflicted individuals is most intense, due to the chronic or sub-acute inflammation of the eyelids and also to the accompanying iritis. The latter, especially, 